\title{
Crackle-sound recording to monitor airway closure and recruitment in ventilated pigs
}

\author{
F. Peták ${ }^{\star}, \#$ W. Habre ${ }^{\Uparrow}$, B. Babik ${ }^{+}$, J. Tolnai* and Z. Hantos*
}

ABSTRACT: It was hypothesised that the recruitment of atelectatic lung areas is signified by changes in the airway and tissue mechanics, and by the appearance of crackle activity attributed to the sudden reopening of collapsed airways. The authors also assumed that the acoustic activity is an earlier indicator of lung recruitment than the change in the overall mechanical state of the lungs.

Six thoracotomised and mechanically ventilated mini-pigs were studied. Low-frequency pulmonary impedance was measured at end-expiratory pauses at transpulmonary pressures of 4 and $1 \mathrm{hPa}$ to estimate airway resistance $(R a w)$ and the coefficient of lung tissue elastance $(H)$, and tracheal sounds were recorded during subsequent slow inflations to $30 \mathrm{hPa}$, in the control state and following increasing doses of i.v. methacholine (Mch).

Raw and $H$ were higher at baseline and increased more in response to Mch at $1 \mathrm{hPa}$ than at $4 \mathrm{hPa}$. The crackles detected during the subsequent inflations were concentrated around and associated with the development of the lower knee of the pressure-volume curve. The number of crackles increased faster following the Mch doses and reached statistical significance earlier than Raw and $\mathrm{H}$.

Crackle recording during mechanical ventilation can be employed as a simple method with which to monitor lung recruitment-derecruitment.

KEYWORDS: Airway reopening, airway resistance, atelectasis, forced oscillations, pulmonary elastance

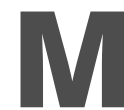
echanical ventilation in clinical situations associated with a lung function impairment requires close monitoring of pulmonary mechanical parameters in order to establish the appropriate therapeutic strategy. In lung diseases, different degrees of bronchoconstriction, airway collapse and parenchymal dysfunction due to surfactant damage and/or oedema formation are observed [1]. Although these mechanisms are often intricate, the resulting lung function impairment in diseases such as asthma [2-5], chronic obstructive pulmonary disease [5-8], cystic fibrosis [5, 9, 10] and acute respiratory distress syndrome [5, 11-18] primarily affects the lung periphery. It is therefore essential to employ a method that provides an objective assessment of the patency of the peripheral airways.

Pulmonary function in mechanically ventilated patients can be assessed by monitoring the ventilator waveforms at the airway opening [2, $3,5,7,9,12,18]$ and by measuring lung mechanical parameters, such as resistive and elastic properties elucidated by the interrupter technique $[8,13,14]$ or the forced oscillatory method [8, 19]. At most, however, these techniques only provide indirect information about the lung periphery. The patency of the peripheral airways can be assessed qualitatively by analysing the lower inflection point of the static pressure-volume $(P-V)$ curve $[1,5,11,15-18$, $20,21]$. Although the shape of the $P-V$ curve around the lower inflection point depends on many factors, such as chest wall tissue nonlinearities [16], surfactant redistribution [17, 22], collapse and reopening of the alveoli and bronchi $[15,21]$, and dynamic hyperinflation [18], it is the analysis of the $P-V$ relationships of the respiratory system that has afforded the most comprehensive data on pulmonary recruitment $[1,15,17$, 20, 21]. Quantitative analysis of the small airway function can also be accomplished by using lungimaging techniques, such as thoracic computed tomography or magnetic resonance imaging [23], although performance of these investigations in a continuous bedside setting is not yet feasible.
AFFILIATIONS

*Dept of Medical Informatics and Engineering, and

${ }^{+}$Dept of Anaesthesiology, University of Szeged, Szeged, Hungary. \#Division of Anaesthesiological Investigations, University of Geneva, and

-Paediatric Anaesthesia Unit, Geneva Children's Hospital, Geneva,

Switzerland.

CORRESPONDENCE

Z. Hantos

Dept of Medical Informatics and

Engineering

University of Szeged

Korányi fasor 9

H-6720 Szeged

Hungary

Fax: 3662544566

E-mail: hantos@dmi.u-szeged.hu

Received:

September 072005

Accepted after revision:

November 082005

SUPPORT STATEMENT

Supported by Hungarian Scientific Research Grants OTKA F38340 and T42971, Hungarian Medical Research Council Grant ETT 519/ 2003, Swiss National Science Foundation Grant 3200-064899.01/ 1 , and a subcontract from US National Science Foundation Grant BES-0402530. 
The present study focuses on the elementary phenomena of the recruitment process. The sudden reopening of closed airways is accompanied by short transient sounds called "crackles"; these acoustic events can be detected during chest auscultation in a number of lung diseases [24-29]. Although crackle sounds have been studied extensively in vitro in collapsed lungs [3033], the potential of acoustic measurements for the detection of airway recruitment in vivo has not been exploited. Accordingly, the authors set out to investigate whether the recording of crackles can be used to detect the involvement of airway closure in compromised lung function in vivo. The changes in airway resistance (Raw) and the coefficient of lung tissue elastance $(H)$ demonstrated that the administration of methacholine (Mch) in increasing doses elicited progressive airway closure, which was facilitated by a decreased lung volume.

\section{METHODS}

\section{Animal preparation}

After approval had been granted by the Ethics and the Animal Care Committees of the Canton of Geneva (Geneva, Switzerland), six adult mini-pigs (17-25 kg) were studied in the supine position. The animals were anaesthetised by the inhalation of sevoflurane (up to $5 \%$ ) until an i.v. line was secured into the ear; thiopentone $\left(10 \mathrm{mg} \cdot \mathrm{kg}^{-1}\right)$ was then injected i.v. The mini-pigs were next tracheotomised with a polyethylene cannula (6.5 mm internal diameter (ID); Portex, Hythe, UK) and mechanically ventilated (Model 900C; Siemens-Elema, Solna, Sweden) with a tidal volume of $7-$ $10 \mathrm{~mL} \cdot \mathrm{kg}^{-1}$ at a frequency of $15 \cdot \mathrm{min}^{-1}$ and an inspired oxygen fraction of 0.3 in air. A continuous infusion of fentanyl $\left(10 \mu \mathrm{g} \cdot \mathrm{kg}^{-1} \cdot \mathrm{h}^{-1}\right)$ via the ear vein was maintained throughout the study to ensure adequate analgesia. Anaesthesia was maintained by the i.v. injection of thiopentone $\left(5 \mathrm{mg} \cdot \mathrm{kg}^{-1}\right)$ every $45-60 \mathrm{~min}$. The carotid artery was prepared surgically in a sterile manner and cannulated (28-gauge catheter; Braun, Melsungen, Germany) for blood sampling and continuous arterial blood pressure monitoring with a calibrated pressure transducer (model 156 PC 06-GW2; Honeywell, Zürich, Switzerland). The jugular vein was prepared in the same way as the femoral artery and cannulated for delivery of the constrictor agonist. Muscle relaxation was achieved by the i.v. administration of pancuronium $\left(0.2 \mathrm{mg} \cdot \mathrm{kg}^{-1}\right)$. The thorax was opened by means of a midline thoracotomy following an additional i.v. bolus of fentanyl $\left(25 \mu \mathrm{g} \cdot \mathrm{kg}^{-1}\right)$ and the ribs were widely retracted. Following chest opening, a positive endexpiratory pressure (PEEP) of $4 \mathrm{hPa}$ was applied.

The airway pressure was measured continuously with a calibrated pressure transducer (Validyne DP 45, Validyne Inc., Northridge, CA, USA). The rectal temperature, monitored with a temperature sensor (Thermalert, model TH-8; Physitemp, Clifton, NJ, USA), was maintained at $37 \pm 0.5^{\circ} \mathrm{C}$ with a heating pad (Miostar, Zürich, Switzerland).

Arterial blood samples were analysed radiometrically (model 505; Acid Base Laboratory, Copenhagen, Denmark) and, if necessary, the mechanical ventilation parameters were adjusted to maintain normal gas exchange. The concentrations of $\mathrm{O}_{2}$ and $\mathrm{CO}_{2}$ were monitored throughout the study (Ultima $^{\mathrm{TM}}$; Datex/Instrumentarium, Helsinki, Finland).

\section{Measurement apparatus}

The set-up used for the forced oscillatory impedance measurements and the recording of intratracheal crackle sounds is shown schematically in figure 1.

\section{Forced oscillations}

The measurement system for collection of the input impedance spectra of the pulmonary system $(Z \mathrm{~L})$ in the mini-pigs was similar to that used previously in other mammals and humans $[30,34]$. Briefly, the tracheal cannula was detached from the respirator and connected to a loudspeaker-in-box system at end expiration. The pressure in the box chambers was set to the level of PEEP to keep the mean transpulmonary pressure $(P \mathrm{~L})$ constant during the measurements. The loudspeaker delivered a computer-generated small-amplitude $(<1 \mathrm{hPa})$ pseudo-random signal between $0.5-21 \mathrm{~Hz}$ through a screen pneumotachograph (11 mm ID), which was used to measure the gas flow $\left(V^{\prime}\right)$ with a differential pressure transducer (model 33NA002D; ICSensors, Malpitas, CA, USA). An identical pressure transducer was used to measure the tracheal pressure with reference to atmosphere $(P \mathrm{~L})$ via a catheter positioned 1$2 \mathrm{~cm}$ beyond the end of the endotracheal tube.

The $P \mathrm{~L}$ and $V^{\prime}$ signals were low-pass filtered at $25 \mathrm{~Hz}$ and sampled with an analogue-digital board of a microcomputer at a rate of $256 \mathrm{~Hz}$. The inspired volume was obtained by numerical integration of $V^{\prime}$. Fast Fourier transformation with 4s time windows and $95 \%$ overlapping was used to calculate $Z \mathrm{~L}$ $\left(Z \mathrm{~L}=P \mathrm{~L} / V^{\prime}\right)$ from the 10 -s recordings.

\section{Estimation of airway and parenchymal parameters}

The airway and parenchymal mechanical properties were separated by fitting a model [34] to the ZL spectra by minimising the differences between the measured and modelled impedance values. The model consisted of an airway compartment containing Raw and Iaw (airway inertance), and a constant-phase tissue unit characterised by damping $(\mathrm{G})$ and $H$ :

$$
\mathrm{ZL}=R a w+j \omega I a w+(G-j H) / \omega^{\alpha}
$$

where $\mathrm{j}$ is the imaginary unit, $\omega$ is the angular frequency $(2 \pi f)$, and $\alpha$ is $(2 / \pi) \arctan (H / G)$.

\section{Crackle measurements}

The technique for the measurement of the sound pressure field generated by airway reopenings was similar to that described previously [30, 32]. A commercial miniature microphone $(5 \times 5 \mathrm{~mm})$ was suspended beyond the end of the tracheal cannula for the recording of tracheal sounds during slow inflations. The electrical signal of the microphone was amplified and sampled at a rate of $22,050 \mathrm{~Hz}$ by another computer.

The sound recordings were first high-pass filtered at $2 \mathrm{kHz}$ in order to enhance the sharp initial transients of the crackles and suppress the cardiac noise [30], thereby improving the temporal resolution of the superimposed crackles. Figure 2 presents an example of the original sound, the high-pass filtered sound, and the lung inflation pressure and volume following the i.v. injection of a $40 \mu \mathrm{g} \cdot \mathrm{kg}^{-1} \mathrm{Mch}$ bolus when a PEEP of $4 \mathrm{hPa}$ was maintained. It can be seen that, although the cardiac noise largely masked the crackles in the raw 


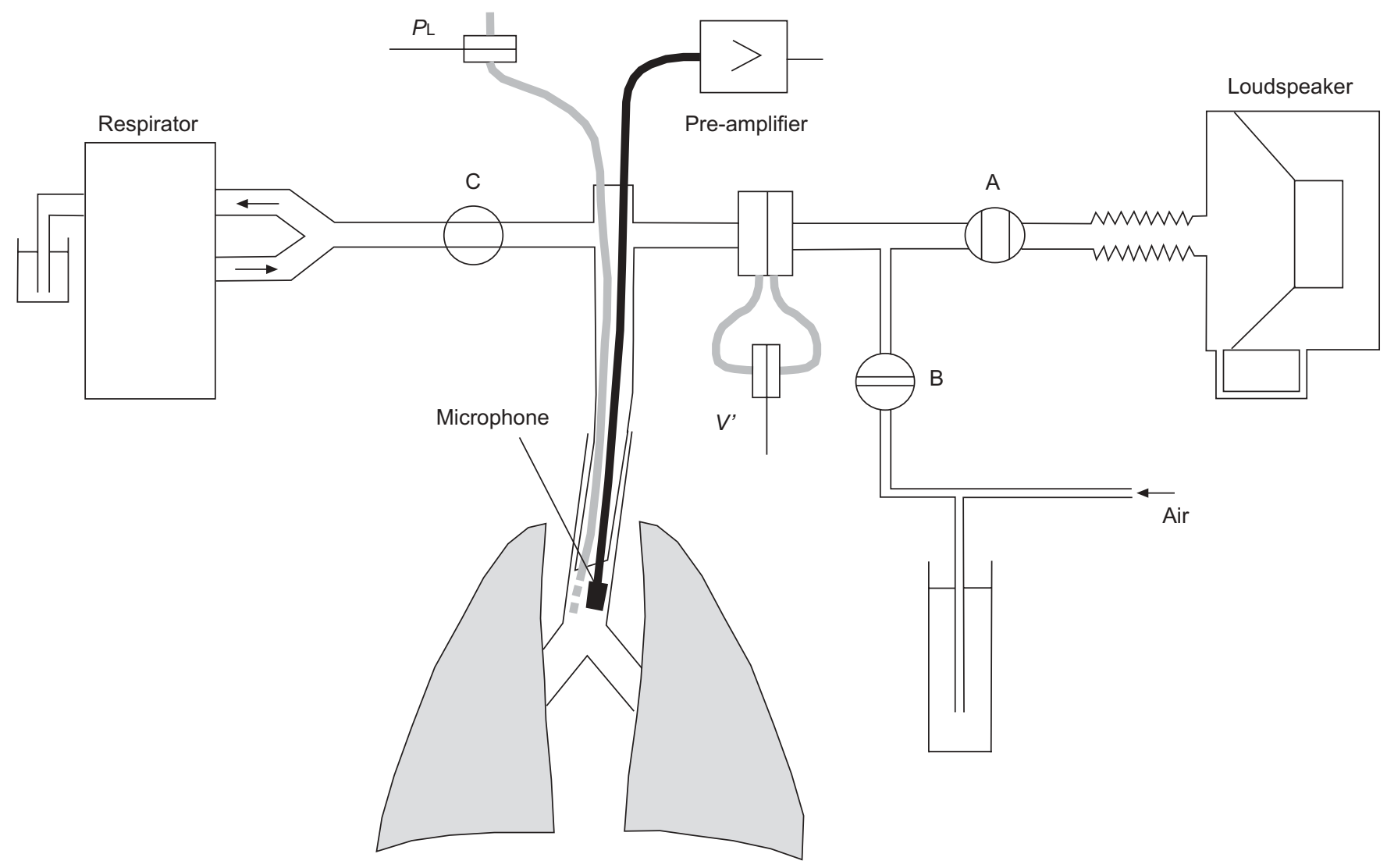

FIGURE 1. Experimental set-up for the measurement of pulmonary input impedance and crackles in the pigs. Taps $A, B$ and $C$ were adjusted according to the phases of ventilation, forced oscillation or slow inflation. $\mathrm{PL}$ : transpulmonary pressure; $V^{\prime}$ : gas flow.

recording, the high-pass filtering diminished the cardiac noise in the tracheal-sound recording. The majority of the crackles, including the most intense ones, appeared in the first third of the inflation. After pre-processing, the maximum levels of background noise were estimated in each recording from the baseline and the end-inflation segments that were free of crackles, and a threshold was determined for the minimum crackle amplitude. The recordings were then divided into short intervals and the sound energy was computed for each interval. The occurrence of a crackle was defined as when the increase in sound energy in two successive intervals exceeded a preset value (fig. 3). During the crackle measurements, the $P \mathrm{~L}$ and $V^{\prime}$ signals were also recorded to monitor the lung inflation pressure and volume.

\section{Study protocol}

Before the measurements, two inspiratory cycles were superimposed to standardise the volume history of the lungs. The mechanical ventilation was suspended at a PEEP level of $4 \mathrm{hPa}$, and $\mathrm{ZL}$ was recorded during the resulting short (10-s) apnoeic period. Before mechanical ventilation was resumed, the lungs were slowly (over $\sim 45 \mathrm{~s}$ ) inflated to a peak pressure of $30 \mathrm{hPa}$, during which period the intratracheal crackles were recorded. Following an $\sim 2-5$-min period of mechanical ventilation, the baseline $\mathrm{ZL}$ and crackle measurements were repeated. Resumed mechanical ventilation was followed by the i.v. administration of a $5 \mu \mathrm{g} \cdot \mathrm{kg}^{-1} \mathrm{Mch}$ bolus. The crackles were recorded $30 \mathrm{~s}$ following the injection, $\mathrm{ZL}$ and immediately afterwards. Subsequent Mch challenges were made in the same way, by administering increasing doses of Mch: 10, 20 and $40 \mu \mathrm{g} \cdot \mathrm{kg}^{-1}$. After completion of the Mch challenges at a PEEP level of $4 \mathrm{hPa}$, PEEP was decreased to $1 \mathrm{hPa}$ to facilitate lung derecruitment. The experimental procedure was then repeated while this pressure level was maintained during the $\mathrm{ZL}$ recordings, and the subsequent inflation was also started from $1 \mathrm{hPa}$.

The ZL data measured under the control conditions were averaged and fitted by the model. The numbers of crackles obtained in the two baseline recordings were also averaged. The model parameters obtained from the ZL spectra collected following the Mch challenges were used to characterise the lung mechanics under these conditions. The lack of mechanical ventilation between the $Z_{L}$ measurement and the crackle recording guaranteed that these measurements reflected the same lung condition.

\section{Statistical analysis}

The precision of the parameters is expressed as mean \pm SEM. The Kolmogorov-Smirnov test was used to test data for normality. Two-way repeated measures ANOVA using a linear mixed model was used to test significance with two within-subject factors: the Mch dose and the PEEP level. In the mixed model, a composite covariance model with separate 

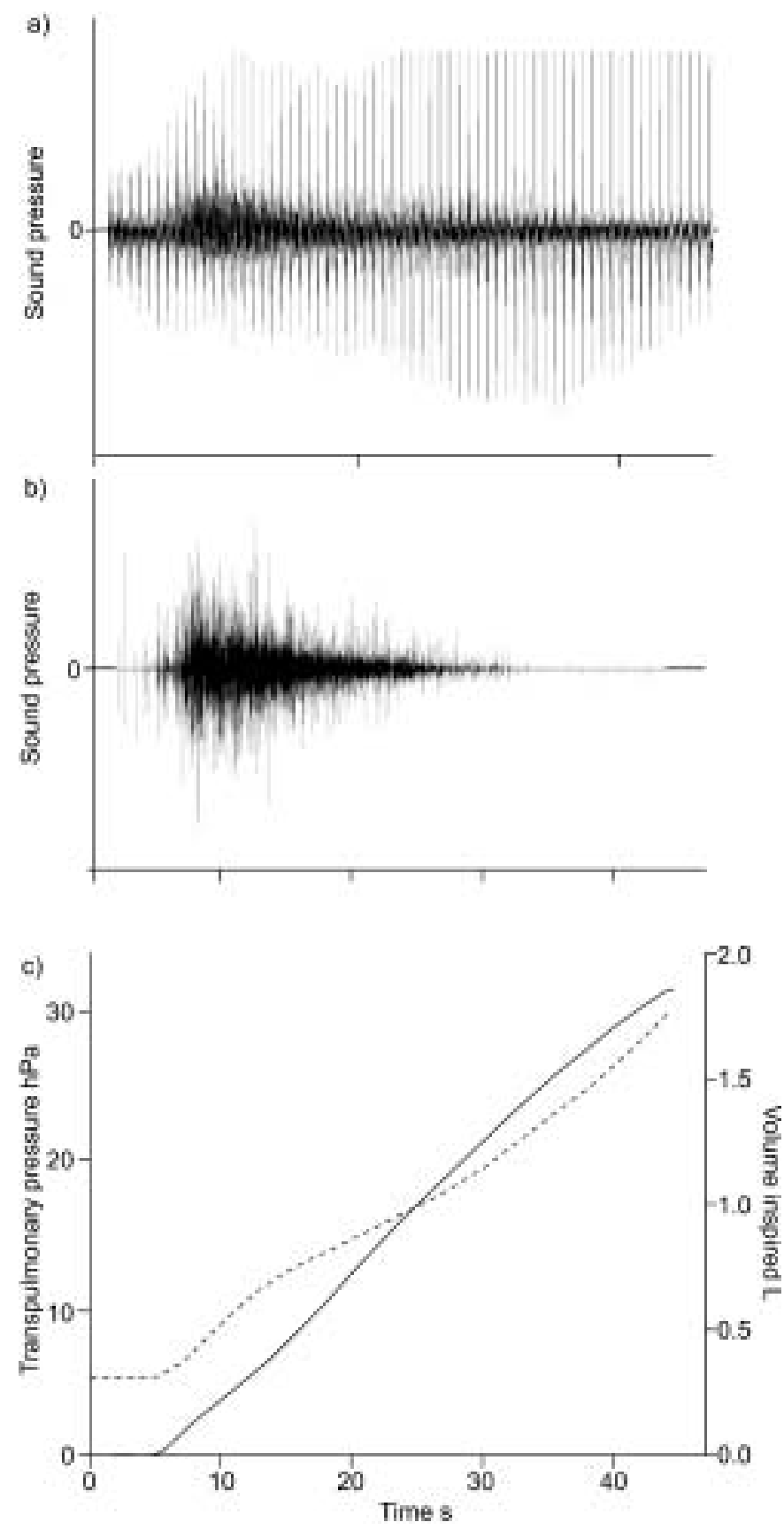

FIGURE 2. Tracings of a) the original and b) the high-pass filtered crackle sound pressure, with c) the inspired volume ( - ) and transpulmonary pressure (- . - - ) during the inflation of a lung.

covariance structures was specified for each of the repeat factors: equal correlations were assumed for the PEEP and a first-order autoregressive covariance structure was applied for the Mch dose. The choice of these covariance models was verified with likelihood ratio tests. For pairwise comparisons, $95 \%$ confidence intervals for the differences were computed by taking into account the significant interactions between the factors. Since the crackle number was not normally distributed, the changes in this parameter were tested after logarithmic transformation. The significance level was set at $\mathrm{p}<0.05$.

\section{RESULTS}

The pulmonary mechanical parameters under control conditions and following Mch challenges at both mean PL levels are presented in figure 4 . With the exception of Iaw, all parameters were greater at the low $P_{\mathrm{L}}$ than those at $4 \mathrm{hPa}$. The response to Mch was more pronounced when the low lung volume was maintained: the parameter values at $40 \mu \mathrm{g} \cdot \mathrm{kg}^{-1}$ Mch, expressed as percentages of the control values, were significantly higher at the mean $P \mathrm{~L}$ of $1 \mathrm{hPa}$ than at $4 \mathrm{hPa}$ (Raw: $1,165 \pm 188 \%$ versus $602 \pm 162 \%, p=0.045 ; \mathrm{G}: 679 \pm 141 \%$ versus $407 \pm 94 \%, p=0.031$; and $H$ : $112 \pm 28 \%$ versus $84 \pm 29 \%$, $p=0.040$ ). Iaw did not change statistically significantly after any of the Mch doses administered at the PL of $4 \mathrm{hPa}$, but it fell significantly at the highest Mch dose at $1 \mathrm{hPa}$ $(-859 \pm 364 \%)$.

An example of the inflation $P \mathrm{~L}-V$ curves and the distributions of the number of crackles, obtained under the control conditions and after the two highest doses of Mch at both $P \mathrm{~L}$ levels, is presented in figure 5 . At a $P \mathrm{~L}$ of $4 \mathrm{hPa}$, the bottom knee (the lower inflexion point) of the $P_{\mathrm{L}}-V$ diagram was not apparent until the highest doses of Mch, whereas it was
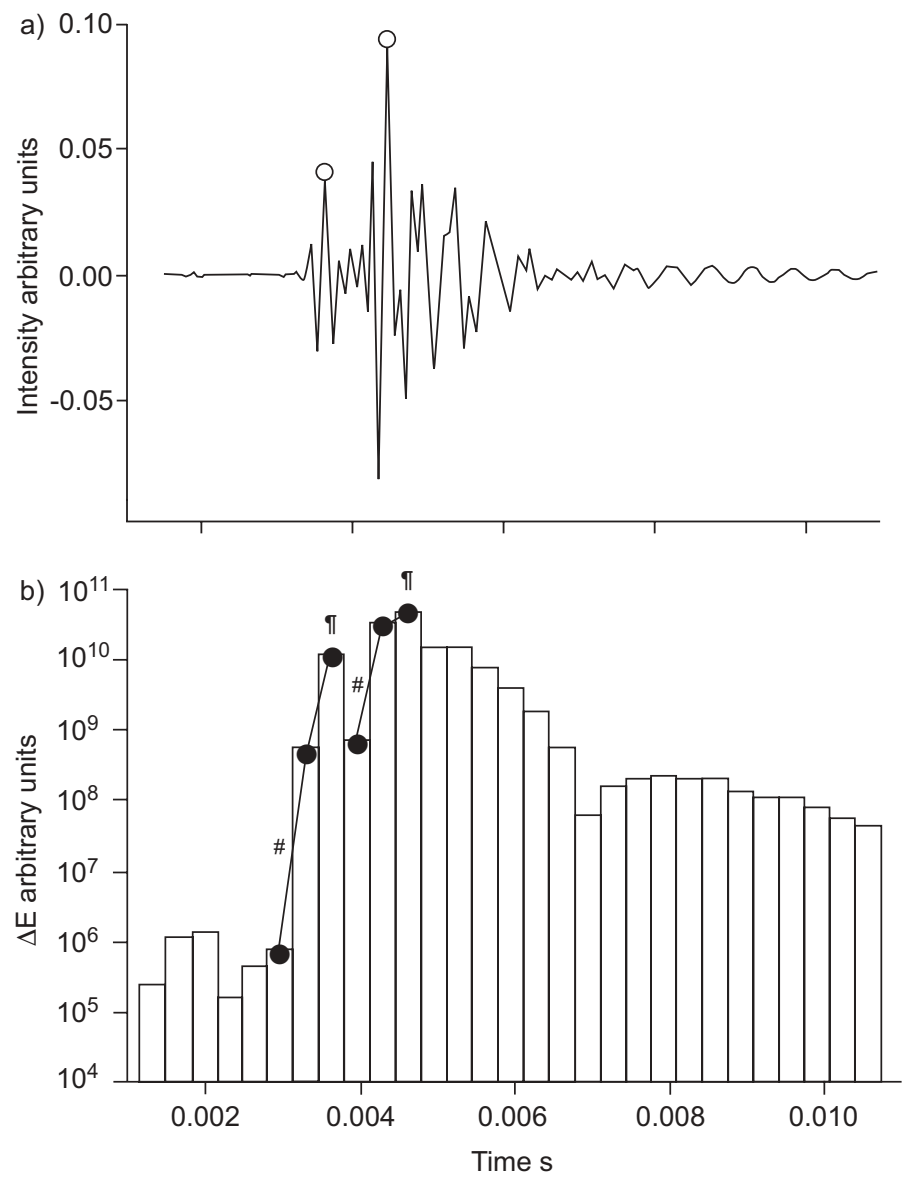

FIGURE 3. a) A short segment of sound recording with superimposing crackles to illustrate the method of identification of the location and amplitude of crackles $(O)$. b) Sound energy $(\Delta E)$ is calculated for successive 0.33-ms intervals. A crackle is identified when the increase in $\Delta \mathrm{E}$ between two successive intervals exceeds a pre-determined (e.g. a three-fold) value $(\#)$; if there is a further increase, the crackle amplitude is taken as the extreme value in the next interval ( $\left.{ }^{(}\right)$. 

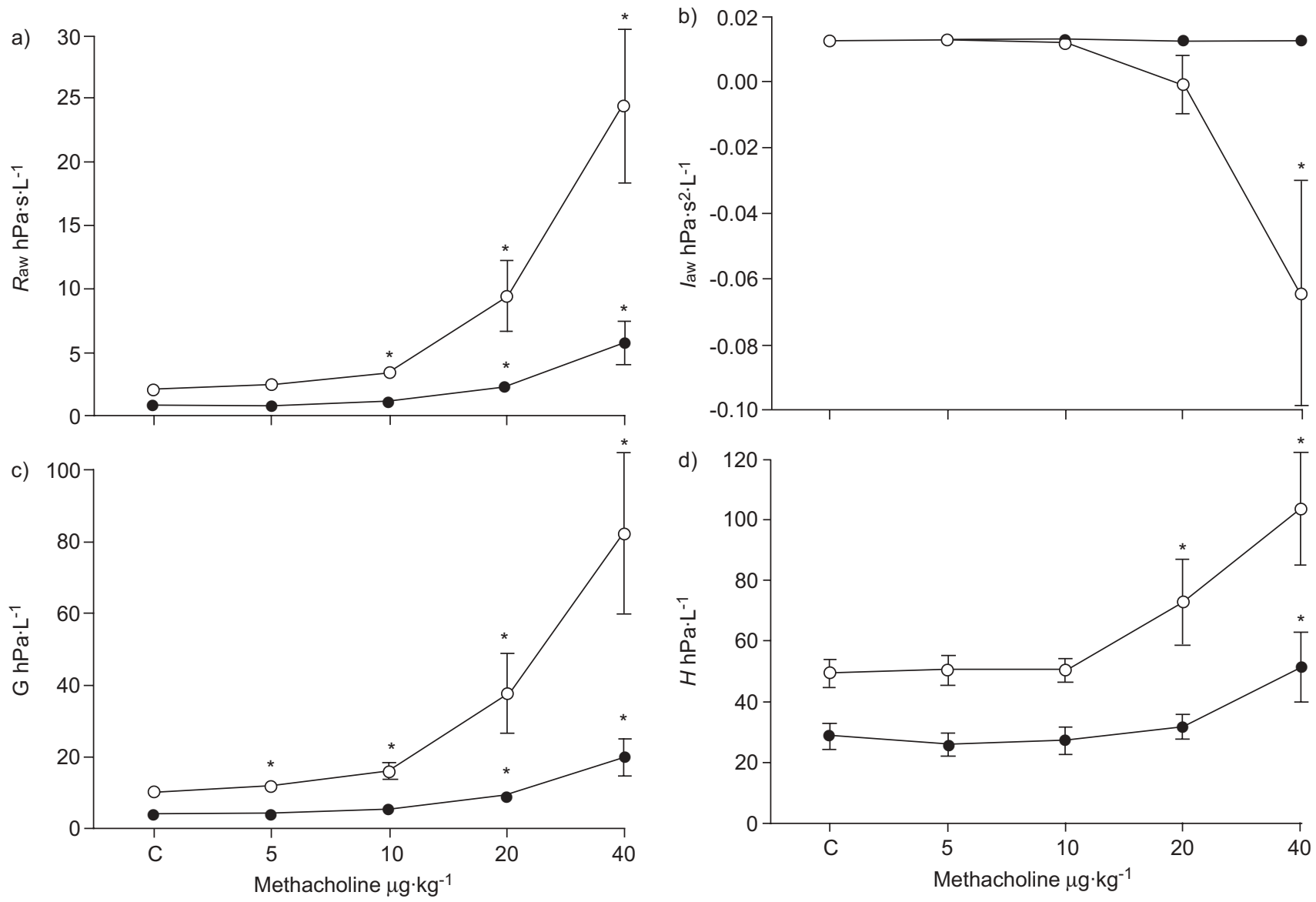

FIGURE 4. a) Airway resistance (Raw) and b) inertance (law), c) tissue damping (G) and d) elastance $(H)$ under the control conditions (C) and following the administration of increasing boluses of methacholine, estimated at mean transpulmonary pressures $(P L)$ of $4 \mathrm{hPa}(\bullet)$ and $1 \mathrm{hPa}(O)$. Data are presented as mean \pm SEM in the six pigs *: $p<0.05$

typically observed even under the control conditions at $1 \mathrm{hPa}$. It is worth noting that, in general, crackle intensity increased significantly before the $P_{\mathrm{L}}-V$ curve exhibited any alteration indicative of the development of the bottom knee (fig. $5 \mathrm{c}$ ). The histograms of the crackles exhibited their maxima at or slightly above the bottom knee and decayed rapidly around the highest slope of the $P_{\mathrm{L}}-V$ curve. The crackles disappeared before the upper knee (the upper inflexion point) of the $P_{\mathrm{L}}-V$ diagram was reached.

The relationships between the values of Raw measured after the Mch challenges at both mean $P_{\mathrm{L}}$ and the crackle number recorded during the subsequent inflations are depicted in figure 6a. Increasing doses of Mch induced progressive increases in both Raw and crackle number, with the elevations from the control values first being statistically significant in the crackles. The decrease in PL led to increases in both Raw and crackle intensity. Similar relationships can be observed between $H$ and crackle number (fig 6b), where the faster increase in crackle number as compared with that in $H$ is more pronounced, especially at a $P \mathrm{~L}$ of $4 \mathrm{hPa}$; the number of crackles is statistically significantly higher than the control level at the first dose of Mch, whereas $H$ reaches statistical significance only at the second-highest dose. There is also a marked difference between the maximum changes in the number of crackles and $H$, with an average 38-fold rise in the crackle number between the control level and the highest Mch dose, whereas the corresponding increase in $H$ is only around twofold. Similar relationships were found between $G$ and the number of crackles (data not shown). The earlier response in the crackle number to the constrictor challenge, as compared with the changes in the pulmonary mechanical parameters, is less marked at the lower lung volume $(P \mathrm{~L}$ of $1 \mathrm{hPa})$, where the crackle activity was already considerable $(>1,000)$ under the control conditions. The mean values and $95 \%$ confidence intervals for the differences in $R a w, H$ and the natural logarithm of the number of crackles are listed for both mean $P \mathrm{~L}$ levels and all Mch doses in the supplementary data available online.

The pulmonary changes evoked by the two series of Mch challenges were fairly reversible: values slightly elevated above the control levels were observed only in $H(31.5 \pm 4.7$ versus $\left.28.5 \pm 4.2 \mathrm{hPa} \cdot \mathrm{l}^{-1} ; \mathrm{p}=0.006\right)$ and in the number of crackles $(253 \pm 310$ versus $86 \pm 26 ; \mathrm{p}=0.09)$.

\section{DISCUSSION}

In order to characterise the recruitment processes during an acute pulmonary constriction in mechanically ventilated animals, intratracheal recordings of crackles during slow 

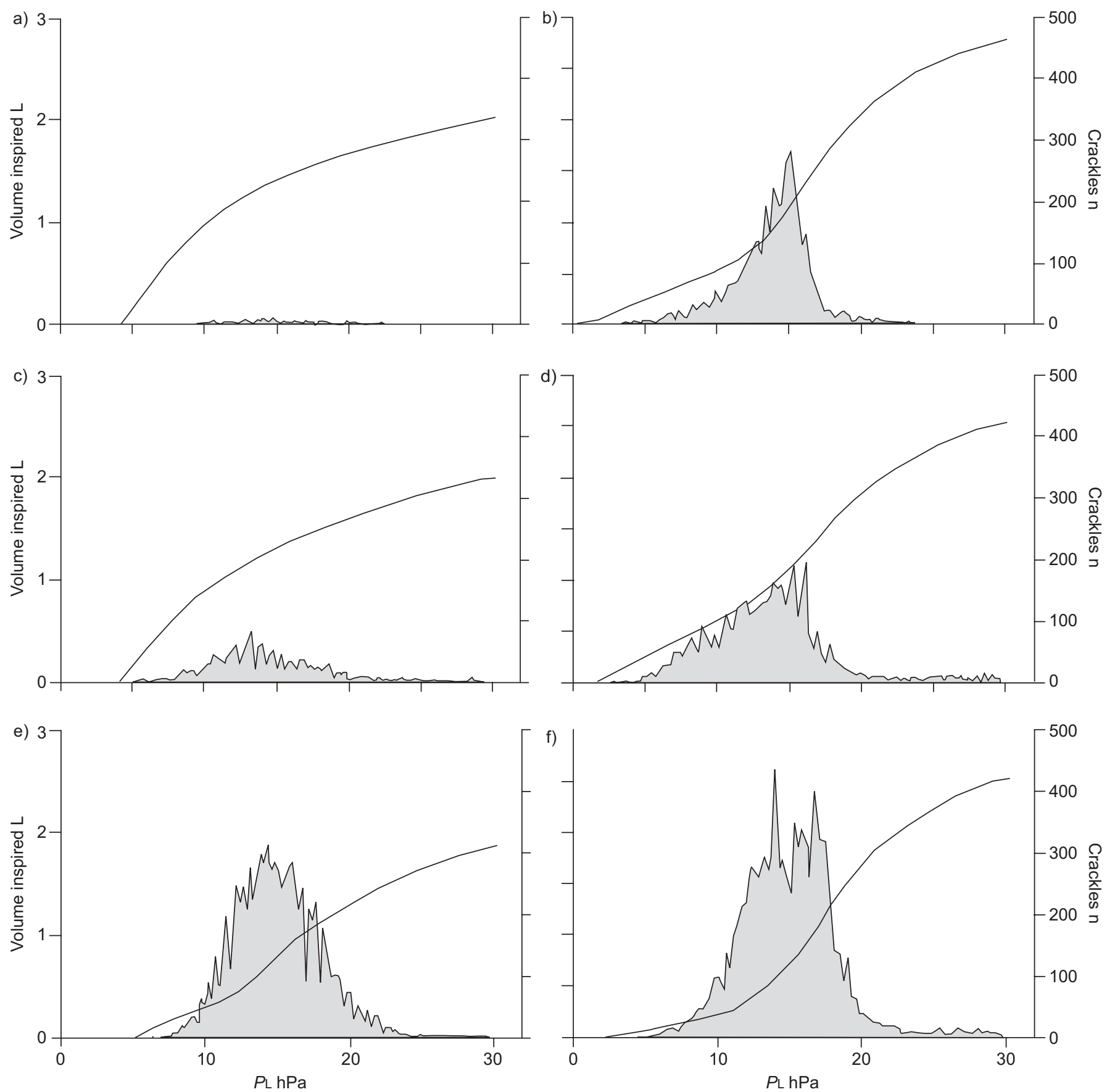

FIGURE 5. Inspired volume and number of crackles versus transpulmonary pressure $(P L)$ from a typical experiment. a, c and e) show inflations from a $P L$ of $4 \mathrm{hPa}$ under the control conditions and after 20 and $40 \mathrm{mg} \cdot \mathrm{kg}^{-1}$ of methacholine, respectively. b, $\mathrm{d}$ and f) relate to the corresponding inflations from a $P L$ of $1 \mathrm{hPa}$ in the same animal.

inflations were combined with measurements of the preinflation oscillatory mechanics of the lungs. Airway closure was generated by lowering the lung volume and/or inducing lung constriction with Mch. The results of the experiments revealed that: 1) the impairment in lung mechanics and the development of the lower inflexion point of the $P \mathrm{~L}-V$ curve were always associated with a significant increase in crackle activity; 2) the magnitude of the increases in the number of crackles was far greater than those observed in the Raw and pulmonary $H$, both following the lung volume decrease and during the constrictor responses of the lungs; and 3) the elevations in the crackle activity preceded those in the pulmonary mechanical parameters.

In order to quantify the reopening of lung units during obstructive disorders in mechanically ventilated mini-pigs, a crackle measurement technique was adopted that was previously employed in excised dog lungs [30]. Although it has been proposed that crackles are generated by the abrupt reopening of lung units [24, 26, 29], evidence has been 

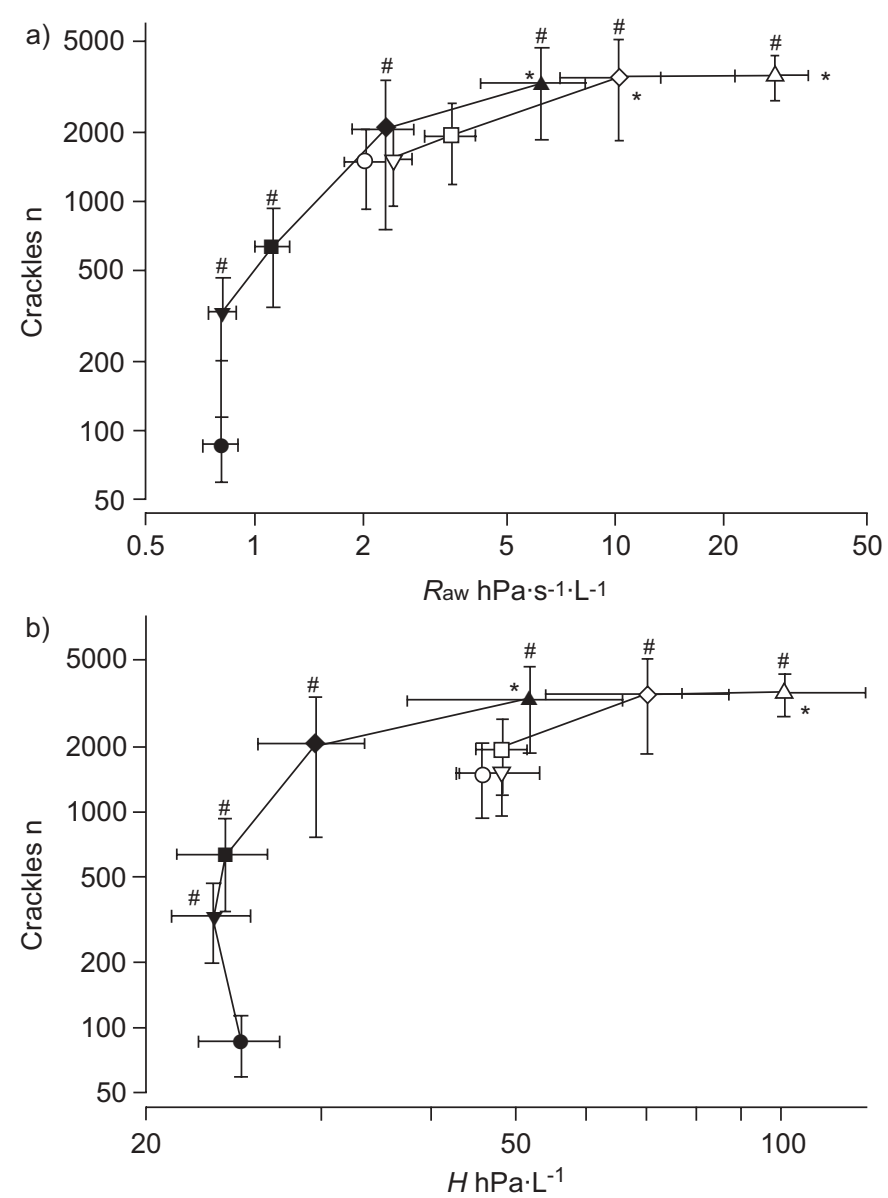

FIGURE 6. Relationship between a) airway resistance (Raw) and the number of crackles and between b) tissue elastance $(H)$ and the number of crackles in the six mini-pigs under control conditions and following the administration of increasing doses of methacholine (Mch). $\bullet$ : control, positive end-expiratory pressure (PEEP) of $4 \mathrm{hPa} ; \mathbf{\nabla}$ : Mch $5 \mu \mathrm{g} \cdot \mathrm{kg}^{-1}$, PEEP of $4 \mathrm{hPa} ; \mathbf{\square}:$ Mch $10 \mu \mathrm{g} \cdot \mathrm{kg}^{-1}$, PEEP of $4 \mathrm{hPa}$; Mch $20 \mu \mathrm{g} \cdot \mathrm{kg}^{-1}$, PEEP of $4 \mathrm{hPa}$; $\mathbf{\Lambda}$ : Mch $40 \mu \mathrm{g} \cdot \mathrm{kg}^{-1}$, PEEP of $4 \mathrm{hPa}$; O: control, PEEP of $1 \mathrm{hPa} ; \nabla$ : Mch $5 \mu \mathrm{g} \cdot \mathrm{kg}^{-1}$, PEEP of $1 \mathrm{hPa}$; $\square$ : Mch $10 \mu \mathrm{g} \cdot \mathrm{kg}^{-1}$, PEEP of $1 \mathrm{hPa} ; \diamond:$ Mch $20 \mu \mathrm{g} \cdot \mathrm{kg}^{-1}$, PEEP of $1 \mathrm{hPa} ; \triangle:$ Mch $40 \mu \mathrm{g} \cdot \mathrm{kg}^{-1}$, PEEP of $1 \mathrm{hPa}$. * and ${ }^{\#}$ : indicate values of Raw or $\mathrm{H}$ and the number of crackles, respectively, that are significantly different $(p<0.05)$ from the corresponding control data.

presented only recently that lung crackles originate from the sudden reopening of the conducting airways [30,33]. Since the acoustic events identified in the present experiments are very similar to those described previously $[30,33]$, it is assumed that they also originate from the opening of small lung structures.

Lung sounds are usually detected by auscultation on the chest surface; hence, preferentially the acoustic events occurring in the adjacent peripheral region and passing through the local pulmonary and chest wall tissues are sensed. These sounds therefore relate to the specific peripheral area, in contrast with the sounds recorded in the trachea, which are all transmitted from the source through a gaseous medium to the central airway and attenuated by every bifurcation between the source and the recording site. As the intensity of a crackle is related to the size of the opening airway, a higher number of peripheral airways would produce smaller crackles and involve more attenuation points. These factors and the actual level of noise determine the acoustic depth of the crackle-recording method, i.e. the generation number of the bronchi whose reopening sounds can still be detected at the airway opening. Although the cardiac sounds as the major source of noise could be completely filtered out because of their distinct spectral features, the environmental noise in the laboratory was more significant than that in an isolated lung measurement, where efficient acoustic isolation can be achieved. Accordingly, the fact that the crackle number plateaued (while Raw and $H$ further increased) with increasing doses of Mch, may reflect the limit set by the noise to the sensitivity of crackle detection, and explain why the progression of reopenings towards the periphery could be followed until the number of crackles reached a value of $\sim 4,000$ (corresponding to the 11th airway generation). Although the acoustic tracking of the recruitment process may have been incomplete, it is perhaps more important that the acoustic method indicated the occurrence of airway closure at an early stage when changes in the pulmonary mechanical parameters were still not apparent. The explanation for the higher sensitivity of the acoustic measurements lies in the fact that the closure of a relatively small number of peripheral airways does not lead to appreciable increases in total Raw and $H$ because of the high number of parallel lung units, whereas every single airway opening that results in an above-threshold crackle is detected in the central airway.

Previous studies on the respiratory mechanics in pigs employed measurements during tidal ventilation $[35,36]$. The forced oscillation method selected in the present investigations offered a more accurate means of characterising the mechanical state of the lungs at a given $P \mathrm{~L}$, since the smallamplitude oscillations at the airway opening were unlikely to lead to recruitment-derecruitment during the measurement.

The dose-dependent changes in ZL in response to Mch were similar to those observed in other species [37-40]: the elevations in Raw exceeded those in $H$, which indicated a significant bronchoconstriction, leading to a smaller degree of closure of lung units. The responses to Mch were enhanced at the lower mean $P \mathrm{~L}$, in agreement with those studies that reported greater lung responses in the presence of a low lung inflation pressure [41], where the disproportional increases in $\mathrm{G}$ as compared with those in $H$, and the sharp fall in law at the highest doses of Mch, indicate the greatly increased inhomogeneity of the peripheral airway constriction [40]. Use of open-chest preparation made it possible not only to exclude the chest wall mechanical properties, but also to lower the lung volume below the closing volume, thereby facilitating closure of the airways even without a bronchoconstrictor challenge. Indeed, re-inflation from $P \mathrm{~L}$ of $1 \mathrm{hPa}$ under control conditions resulted in a reopening activity comparable in the number of crackles to that reached at the third dose of Mch at the higher PL level.

The aims of this study were to evaluate the effect of airway closure on the pulmonary mechanics at different mean lung volumes and degrees of bronchoconstriction, and to quantify the recruitment via the crackle activity recorded during the subsequent slow inflations. The experimental model was therefore chosen to mimic situations characterised by airway obstruction, such as in anaphylactic reactions, the exacerbation 
of asthma or chronic obstructive pulmonary disease, and was not intended to include capillary filtration/resorption abnormalities typical of acute lung injury. Excessive intrabronchial fluid and foam production in pulmonary oedema may increase the number of crackle-like sounds not uniquely connected to airway opening; bubbles may pop up in large numbers during both inspiration and expiration, and produce transient sounds reminiscent of crackles [32]. This did not happen in the present study; gross examination of the lungs and major airways revealed no fluid accumulation, and the $R$ aw and $H$ values had almost completely recovered by the beginning of the second sequence of Mch challenges.

In conclusion, the present study demonstrated that the quantification of airway closure on the basis of subsequent recruitment is feasible by monitoring intratracheal crackle sounds in vivo. The measurements revealed the importance of airway closure in the deterioration of the lung mechanical parameters following the administration of methacholine at a normal lung volume, and especially at a lung volume below the closing volume. Since the number of crackles increased significantly before any change occurred in the airway resistance, the pulmonary elastance or the shape of the transpulmonary pressure-volume curve, lung-sound recording appears to be a sensitive tool with which to indicate early impairments in the mechanics of the lung periphery. Thus, crackle recordings may have the potential to serve as a bedside monitoring tool for detection of the cyclic recruitmentderecruitment of the airways during mechanical ventilation, and hence contribute to the guidance of the optimal ventilation strategy.

\section{REFERENCES}

1 de Chazal I, Hubmayr D. Novel aspects of pulmonary mechanics in intensive care. Br J Anaesth 2003; 91: 81-91.

2 Leatherman JW, McArthur C, Shapiro RS. Effect of prolongation of expiratory time on dynamic hyperinflation in mechanically ventilated patients with severe asthma. Crit Care Med 2004; 32: 1542-1545.

3 Manthous CA, Goulding P. The effect of volume infusion on dead space in mechanically ventilated patients with severe asthma. Chest 1997; 112: 843-846.

4 Williams TJ, Tuxen DV, Scheinkestel CD, Czarny D, Bowes G. Risk factors for morbidity in mechanically ventilated patients with acute severe asthma. Am Rev Respir Dis 1992; 146: 607-615.

5 Dhand R. Ventilator graphics and respiratory mechanics in the patient with obstructive lung disease. Respir Care 2005; 50: 246-61.

6 Kaczka DW, Ingenito EP, Body SC, et al. Inspiratory lung impedance in COPD: effects of PEEP and immediate impact of lung volume reduction surgery. J Appl Physiol 2001; 90: 1833-1841.

7 van den Berg B, Stam H, Bogaard JM. Effects of PEEP on respiratory mechanics in patients with COPD on mechanical ventilation. Eur Respir J 1991; 4: 561-567.

8 Farre R, Ferrer M, Rotger M, Torres A, Navajas D. Respiratory mechanics in ventilated COPD patients: forced oscillation versus occlusion techniques. Eur Respir J 1998; 12: $170-176$
9 Fauroux B, Louis B, Hart N, et al. The effect of back-up rate during non-invasive ventilation in young patients with cystic fibrosis. Intensive Care Med 2004; 30: 673-681.

10 Sood N, Paradowski LJ, Yankaskas JR. Outcomes of intensive care unit care in adults with cystic fibrosis. Am J Respir Crit Care Med 2001; 163: 335-338.

11 Harris RS, Hess DR, Venegas JG. An objective analysis of the pressure-volume curve in the acute respiratory distress syndrome. Am J Respir Crit Care Med 2000; 161: 432-439.

12 The Acute Respiratory Distress Syndrome Network. Ventilation with lower tidal volumes as compared with traditional tidal volumes for acute lung injury and the acute respiratory distress syndrome. N Engl J Med 2000; 342: 1301-1308.

13 Pelosi P, Cereda M, Foti G, Giacomini M, Pesenti A. Alterations of lung and chest wall mechanics in patients with acute lung injury: effects of positive end-expiratory pressure. Am J Respir Crit Care Med 1995; 152: 531-537.

14 Eissa NT, Ranieri VM, Corbeil C, et al. Analysis of behavior of the respiratory system in ARDS patients: effects of flow, volume, and time. J Appl Physiol 1991; 70: 2719-2729.

15 Maggiore SM, Richard JC, Brochard L. What has been learnt from $\mathrm{P} / \mathrm{V}$ curves in patients with acute lung injury / acute respiratory distress syndrome. Eur Respir J 2003; 22: Suppl. 42, 22s-26s.

16 Mergoni M, Martelli A, Volpi A, Primavera S, Zuccoli P, Rossi A. Impact of positive end-expiratory pressure on chest wall and lung pressure-volume curve in acute respiratory failure. Am J Respir Crit Care Med 1997; 156: 846-54.

17 Jonson B, Richard JC, Straus C, Mancebo J, Lemaire F, Brochard L. Pressure-volume curves and compliance in acute lung injury: evidence of recruitment above the lower inflection point. Am J Respir Crit Care Med 1999; 159: 1172-1178.

18 Vieillard-Baron A, Prin S, Schmitt JM, et al. Pressurevolume curves in acute respiratory distress syndrome: clinical demonstration of the influence of expiratory flow limitation on the initial slope. Am J Respir Crit Care Med 2002; 165: 1107-1112.

19 Navajas D, Farre R, Canet J, Rotger M, Sanchis J. Respiratory input impedance in anesthetized paralyzed patients. J Appl Physiol 1990; 69: 1372-1379.

20 Venegas JG, Harris RS, Simon BA. A comprehensive equation for the pulmonary pressure-volume curve. J Appl Physiol 1998; 84: 389-395.

21 Hickling KG. The pressure-volume curve is greatly modified by recruitment. A mathematical model of ARDS lungs. Am J Respir Crit Care Med 1998; 158: 194-202.

22 Faridy EE. Air opening pressure in fluid-filled lungs. Respir Physiol 1987; 68: 279-291.

23 Maki DD, Gefter WB, Alavi A. Recent advances in pulmonary imaging. Chest 1999; 116: 1388-1402.

24 Nath AR, Capel LH. Inspiratory crackles and mechanical events of breathing. Thorax 1974; 29: 695-698.

25 Piirila P. Changes in crackle characteristics during the clinical course of pneumonia. Chest 1992; 102: 176-183.

26 Forgacs P. Crackles and wheezes. Lancet 1967; 2: 203-205.

27 Piirila P, Sovijarvi AR, Kaisla T, Rajala HM, Katila T. Crackles in patients with fibrosing alveolitis, bronchiectasis, COPD, and heart failure. Chest 1991; 99: 1076-1083. 
28 Pasterkamp H, Kraman SS, Wodicka GR. Respiratory sounds. Advances beyond the stethoscope. Am J Respir Crit Care Med 1997; 156: 974-987.

29 Forgacs P. Breath sounds. Thorax 1978; 33: 681-683.

30 Hantos Z, Tolnai J, Asztalos T, et al. Acoustic evidence of airway opening during recruitment in excised dog lungs. $J$ Appl Physiol 2004; 97: 592-598.

31 Cheng W, DeLong DS, Franz GN, Petsonk EL, Frazer DG. Contribution of opening and closing of lung units to lung hysteresis. Respir Physiol 1995; 102: 205-215.

32 Alencar AM, Hantos Z, Petak F, et al. Scaling behavior in crackle sound during lung inflation. Phys Rev E Stat Phys Plasmas Fluids Relat Interdiscip Topics 1999; 60: 4659-4663.

33 Cheng W, DeLong DS, Franz GN, Petsonk EL, Frazer DG. Discountinuous lung sounds and hysteresis in control and Tween 20-rinsed excised rat lungs. Respir Physiol 1999; 117: 131-140.

34 Hantos Z, Daroczy B, Suki B, Nagy S, Fredberg JJ. Input impedance and peripheral inhomogeneity of dog lungs. $J$ Appl Physiol 1992; 72: 168-178.

35 Fornhem C, Kumlin M, Lundberg JM, Alving K. Allergeninduced late-phase airways obstruction in the pig: mediator release and eosinophil recruitment. Eur Respir J 1995; 8: 1100-1109.

36 Sylvin H, Weitzberg E, Alving K. Endothelin-induced vascular and bronchial effects in pig airways: role in acute allergic responses. J Appl Physiol 2002; 93: 16081615.

37 Tomioka S, Bates JH, Irvin CG. Airway and tissue mechanics in a murine model of asthma: alveolar capsule vs. forced oscillations. J Appl Physiol 2002; 93: 263-270.

38 Tepper R, Sato J, Suki B, Martin JG, Bates JH. Low-frequency pulmonary impedance in rabbits and its response to inhaled methacholine. J Appl Physiol 1992; 73: 290-295.

39 Suki B, Petak F, Adamicza A, Daroczy B, Lutchen KR, Hantos Z. Airway and tissue constrictions are greater in closed than in open-chest conditions. Respir Physiol 1997; 108: 129-141.

40 Lutchen KR, Hantos Z, Petak F, Adamicza A, Suki B. Airway inhomogeneities contribute to apparent lung tissue mechanics during constriction. J Appl Physiol 1996; 80: 1841-1849.

41 Shinozuka N, Nemoto T, Bates JH. Isovolume bronchoconstriction by vagal stimulation in dogs: effects of lung inflation pressure. Respir Physiol 1998; 111: 79-88. 